\title{
An Immunohistochemical Analysis of Peripheral Blood Tissue Specimens from Leukemia Cells: Leukemic Cells of Adult T-cell Leukemia/Lymphoma Express p40Tax Protein of Human T-cell Lymphotropic Virus Type 1 When Entering Reproliferation
}

\begin{abstract}
Kazuhisa Hasui ${ }^{1}$, Atae Utsunomiya ${ }^{2}$, Shuji Izumo ${ }^{3}$, Masamichi Goto ${ }^{4}$, Suguru Yonezawa ${ }^{4}$, Eiichi Sato ${ }^{5}$, Tamotsu Kanzaki ${ }^{6}$ and Fusayoshi Murata ${ }^{1}$

${ }^{1}$ Second Department of Anatomy, Kagoshima University Faculty of Medicine, Kagoshima, Japan, ${ }^{2}$ Department of Hematology, Imamura Bun-in Hospital, Kagoshima, Japan, ${ }^{3}$ Division for Molecular Pathology and Genetic Epidemiology, Center for Chronic Viral Disease, Kagoshima University Faculty of Medicine, Kagoshima, Japan, ${ }^{4}$ Second Department of Pathology, Kagoshima University Faculty of Medicine, Kagoshima, Japan, ${ }^{5}$ Kagoshima University, Kagoshima, Japan and ${ }^{6}$ Department of Dermatology, Kagoshima University Faculty of Medicine, Kagoshima, Japan
\end{abstract}

Received May 6, 2003; accepted June 13, 2003

Human T-cell lymphotropic virus type 1 (HTLV-1) proviral DNA p40Tax (Tax) protein plays an important role in adult T-cell leukemia/lymphoma (ATLL) oncogenesis, but it has yet to be determined whether or not ATLL leukemic cells express Tax. In a study designed to answer this question, we prepared peripheral blood tissue specimens (PBTS) from four acute and seven chronic ATLL cases and three B-cell chronic lymphocyte leukemia (B-CLL) cases, and examined their immunological phenotype and Ki67 labeling index (Ki67LI) by means of antigen-retrieval immunohistochemistry. In three of the chronic ATLL cases, the difference in Ki67LI between leukemic cells that underwent either $3 \mathrm{hr}$, or more than $6 \mathrm{hr}$ of sedimentation and coagulation while preparing PBTS suggested that the Ki67LI in PBTS represents reproliferating cells. Tax expression was examined by means of the ImmunoMax method. In two acute and three chronic type ATLL cases, leukemic cells expressed Tax in parallel with the Ki67LI, suggesting that Tax expression was related to reproliferation in PBTS. Leukemic cells in one case each of acute and chronic type ATLL did not express Tax. In one case of acute ATLL after chemotherapy, some cells expressed Tax among the other cells. These results indicate that ATLL leukemic cells are able to express an extremely small amount of Tax during reproliferation.

Key words: adult T-cell leukemia/lymphoma (ATLL), human T-cell lymphotropic virus type 1

(HTLV-1), p40Tax, modified ImmunoMax, peripheral blood tissue specimen (PBTS)

\section{Introduction}

Adult T-cell leukemia/lymphoma (ATLL) is a human T-cell lymphotropic virus type 1 (HTLV-1)-induced mature T-cell neoplasm [1]. The pathogenicity of HTLV-1 has been shown to depend on its proviral DNA pX-region-related protein p40Tax (Tax) $[2,7,8,12,14,15,17-19,23,25]$. By using a modified ImmunoMax method to detect extremely

Correspondence to: Kazuhisa Hasui, MD, PhD., Second Department of Anatomy, Kagoshima University Faculty of Medicine, Sakuragaoka 8-35-1, Kagoshima 890-8520, Japan. small amounts of Tax [10], it was shown that ATLL lymphoma cells express an extremely small amount of Tax in tissue specimens from many cases [2-4], whereas leukemic ATLL cells were believed not to express Tax $[11,16]$.

This study investigated whether leukemic ATLL cells express Tax by using the modified ImmunoMax method to detect Tax and p27Rex (Rex) [3]. In order to apply the modified ImmunoMax [3] to detect Tax in leukemic ATLL cells, we prepared leukemic ATLL cells by processing naturally sedimented and coagulated white blood cells to paraffin-embedded tissue specimens (peripheral blood tissue specimen: PBTS). 
Here, we report the method to prepare PBTS, the utility of PBTS in detecting the phenotype of leukemic cells, and the application of the modified ImmunoMax method to detect Tax and p27Rex (Rex) in leukemic cells in PBTS of ATLL.

\section{Materials and Methods}

With the informed consent of eight patients with ATLL and of three patients with B-cell chronic lymphocyte leukemia (B-CLL) (Cases A to K, Table 1), PBTS were prepared according to the method described below to examine the phenotype of leukemic cells and the expression of HTLV-1 proviral DNA-related proteins in leukemic cells.

With the informed consent of three patients (Cases 1 to 3) with chronic type ATLL, PBTS were first prepared with different durations of natural sedimentation and coagulation of leukemic cells before fixation in order to see whether PBTS was an appropriate material in which to examine the features of leukemic cells.

The research ethics committee at Kagoshima University Postgraduate School of Medicine approved publication of this study (2003, March).

\section{Peripheral blood tissue specimens (PBTS)}

As shown in Fig. 1, $5 \mathrm{ml}$ of peripheral blood was taken from each patient using a disposable injector. The injector was left in a vertical position for more than $3 \mathrm{hr}$. After removing the cylinder of the injector, buffered $10 \%$ formalin solution was poured into the injector to fix the coagulated white blood cells on the layer of red blood cells. After overnight fixation, the cylinder of coagulated white blood cells with coagulated red blood cells was removed from the injector and was cut into two pieces along the long axis. The two pieces of fixed coagulated white and red blood cells were processed by routine procedures to prepare paraffinembedded peripheral blood tissue specimens (PBTS).

Sections of PBTS were used for this study. Morphological changes of leukemic cells were evaluated in hematoxy-
Table 1. Cases examined

\begin{tabular}{cccll}
\hline No. & Age & Sex & $\begin{array}{c}\text { Hematological } \\
\text { diagnosis }\end{array}$ & $\begin{array}{c}\text { Status of treatment at } \\
\text { sampling peripheral blood }\end{array}$ \\
\hline A & 56 & M & ATLL, acute type & After chemotherapy \\
B & 70 & F & ATLL, chronic type & No treatment \\
C & 67 & F & ATLL, acute type & No treatment \\
D & 58 & F & ATLL, chronic type & No treatment \\
E & 69 & F & ATLL, acute type & No treatment \\
F & 72 & F & ATLL, chronic type & No treatment \\
G & 71 & M & ATLL, chronic type & No treatment \\
H & 64 & F & B-CLL & No treatment \\
I & 74 & F & B-CLL & No treatment \\
J & 73 & M & ATLL, acute type & No treatment \\
K & 71 & M & B-CLL & No treatment \\
\hline
\end{tabular}

lin-eosin (H.E.)-stained sections of PBTS in comparison with Giemsa-stained smear specimens of peripheral blood.

As described above, PBTS requires at least $3 \mathrm{hr}$ for sedimentation and coagulation of leukemic cells. In three cases of chronic type ATLL (Table 4), the effects of sedimentation/coagulation time on the rate of proliferating cells detected by immunohistochemistry against Ki67 antigen (Ki67 labeling index) in PBTS were examined by preparing PBTS from samples where the injectors were left vertically either for $3 \mathrm{hr}$ or for longer than $6 \mathrm{hr}$ before fixation.

\section{Immunohistochemistry to detect the phenotype of leukemia cells and proliferating cells}

The phenotype of leukemic cells was examined by antigen-retrieval (AR) and paraffin-immunohistochemistry (pIHC) in eight cases of ATLL and three cases of B-CLL (Table 1).

Sections of PBTS were deparaffinized, post-fixed in buffered $10 \%$ formalin solution for $30 \mathrm{~min}$ and rinsed in running water. Endogenous peroxidase activity was destroyed by incubating sections in $0.3 \% \mathrm{H}_{2} \mathrm{O}_{2}$ in methanol for $20 \mathrm{~min}$ after deparaffinization or in $3 \% \mathrm{H}_{2} \mathrm{O}_{2}$ in phosphate-buffered saline (PBS) for $5 \mathrm{~min}$ before reaction with primary anti-

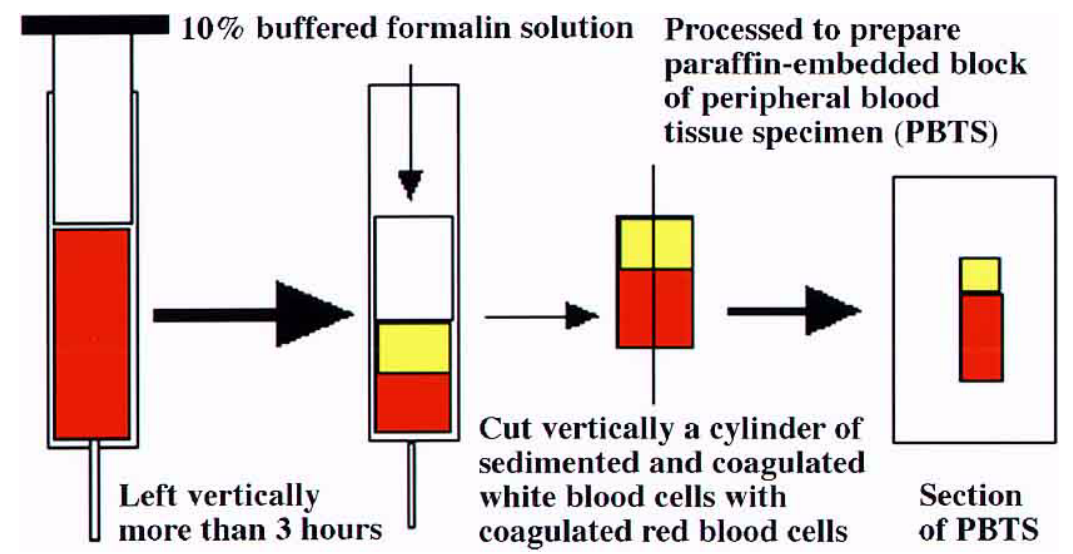

Fig. 1. Peripheral blood tissue specimen (PBTS). PBTS is made by a process depending on sedimentation and coagulation of white blood cells. By employing a disposable injector, aseptic procedures before fixation can be ensured, even in the clinical setting. 
Table 2. Antibodies employed in this study

\begin{tabular}{lll}
\hline \multicolumn{1}{c}{ Antigen } & \multicolumn{1}{c}{ Source } & \multicolumn{1}{c}{ Specificity } \\
\hline CD3 & NOVO NCL-CD3-PS1 & Pan-T-cells \\
CD4 & NOVO NCL-CD4-1F6 & a subset of T-cells \\
CD8 & DAKO M7103 & a subset of T-cells \\
CD5 & NOVO NCL-CD5-4C7 & T-cell and peGC B-cells \\
CD79a & DAKO M7050 & Pan B-cells \\
CD56 & NOVO NCL-CD56-1B6 & Natural killer cells \\
CD68 & DAKO MO876 (=PGM1) & Monocytes and macrophages \\
Muramidase & DAKO A0099 & Muramidase \\
Ki67antigen & NOVO NCL-Ki-67-MM1 Proliferating cells \\
p40Tax WATM-1 & HTLV-1 p40Tax \\
p27Rex Rec-6 & HTLV-1 p27Rex \\
\hline
\end{tabular}

\#1: Supplied by Tanaka Y., Professsor, Ryukyu University, Okinawa, Japan. body. AR was performed by incubating sections in $0.01 \mathrm{M}$ citrate buffer, $\mathrm{pH} 6.0$, and heating for $5 \mathrm{~min}$ at $121^{\circ} \mathrm{C}$ in an autoclave. After cooling the sections by rinsing them in $0.05 \mathrm{M}$ PBS, $\mathrm{pH} 7.6$, sections were reacted with the primary antibodies listed in Table 2 overnight at $4^{\circ} \mathrm{C}$ or for $1 \mathrm{hr}$ at $37^{\circ} \mathrm{C}$. Reacted antibodies were visualized by means of the Elite ABC method (Vector Laboratories) and the 3,3'diaminobenzidine tetrahydrochloride (DAB) $-\mathrm{H}_{2} \mathrm{O}_{2}$ reaction. After nuclear staining with hematoxylin, sections were dehydrated and embedded in plastic medium.

Ki67 labeling index was calculated by counting more than 500 cells as labeled or not labeled in each representative microphotograph (objective, $\times 40$ ) of PBTS specimens processed by anti-Ki67 antigen immunohistochemistry.

Modified ImmunoMax to detect HTLV-1 p40Tax and p27Rex

The modified ImmunoMax method using anti-Tax and anti-Rex rat monoclonal antibodies (WATM-1 [22] and Rec-6 [3]; supplied by Professor Yuetsu Tanaka, Ryukyu
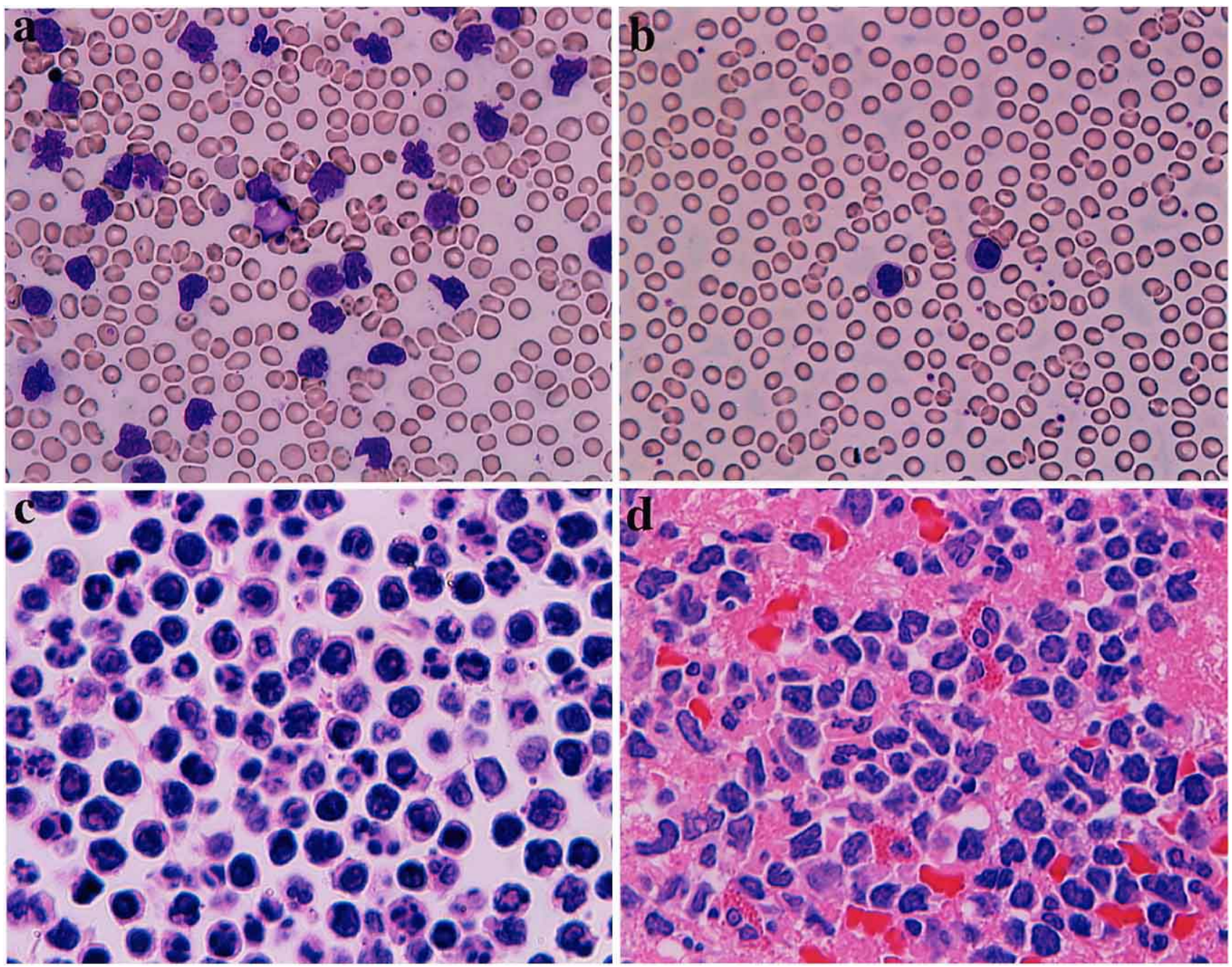

Fig. 2. Smear and peripheral blood tissue specimen (PBTS) of ATLL. a and c: Acute type (a: Giemza-stained smear specimen, $\times 40$, c: H.E.stained PBTS, objective $\times 100$, oil). b and d: Chronic type (b: Giemza-stained smear specimen, $\times 40$, d: H.E.-stained PBTS, objective $\times 100$, oil). Shrinking of leukemic cells is obvious in comparison with Giemza-stained smear specimen and PBTS. 

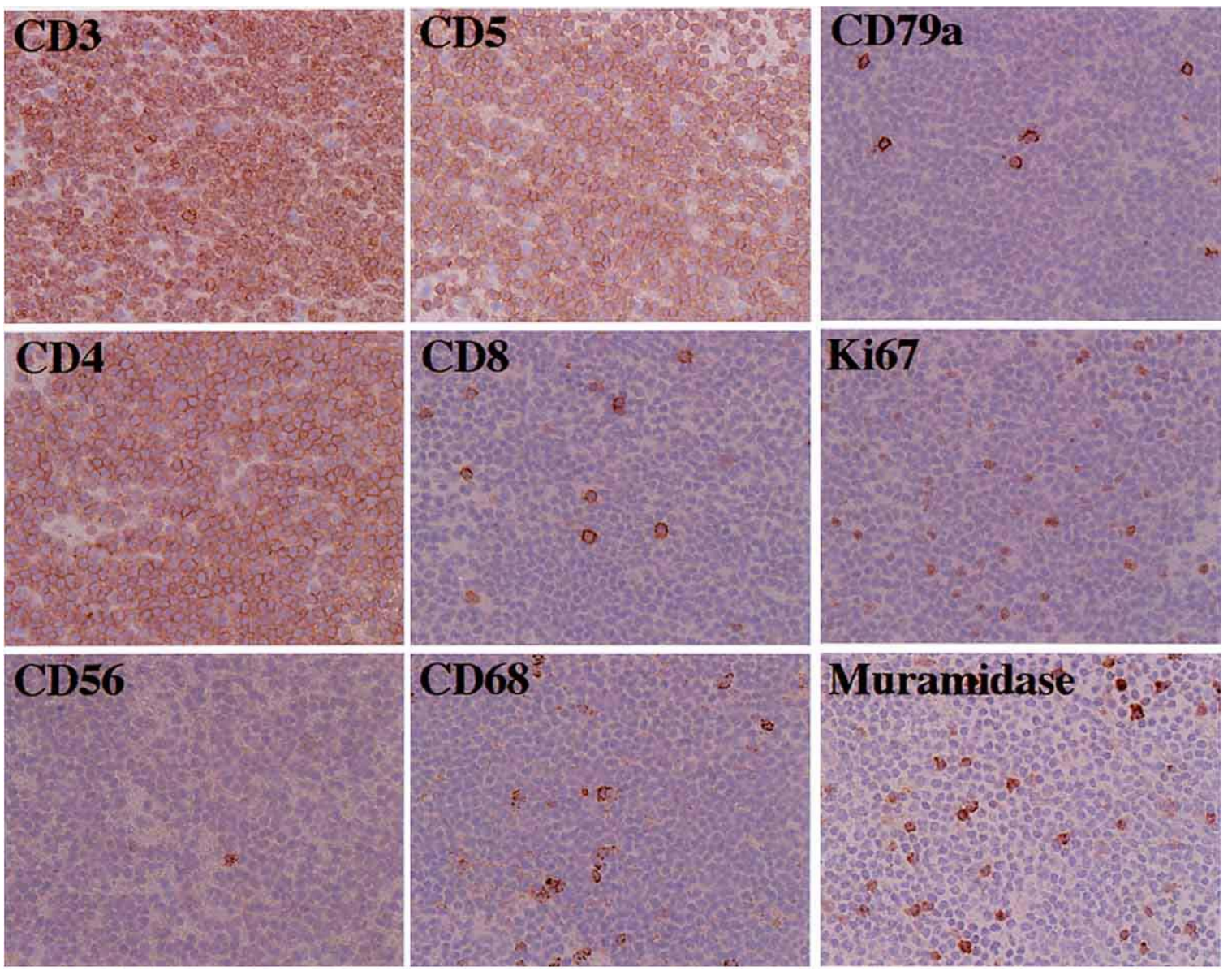

Fig. 3. Antigen-retrieval immunohistochemistry detecting the phenotype of leukemic cells in sections of PBTS. Leukemic cells in a case (Case J in Table 1) of acute type ATLL were positive for CD3, CD5 and CD4. Some cells have nuclei labeled by anti-Ki67 antigen antibody.

University, Okinawa, Japan) has been reported in detail previously $[3,4,9]$. The method for PBTS is described briefly below.

PBTS sections were deparaffinized, post-fixed in buffered $10 \%$ formalin solution for $30 \mathrm{~min}$ and rinsed in PBS. AR was performed by incubating sections in $4 \mathrm{M}$ urea solution and heating for $5 \mathrm{~min}$ after boiling in a pressure cooker under a fume hood with extraction system. After destroying endogenous peroxidase activity with $3 \% \mathrm{H}_{2} \mathrm{O}_{2}$ in PBS, protein blocking (DAKO Non-specific Staining Blocking Reagent, X0909) with $8 \%$ horse serum to mask non-specific reactions was performed for $30 \mathrm{~min}$. Reaction with WATM-1 or Rec-6 was performed overnight at $4{ }^{\circ} \mathrm{C}$. After masking endogenous biotin with a masking solution (DAKO Biotin Blocking System, X0590), reacted primary antibodies were detected by means of a combination of antirat immunoglobulin biotinylated antibody (DAKO, B0468), the DAKO catalyzed signal amplification (CSA) system $(\mathrm{K} 1500)$ and the DAB- $\mathrm{H}_{2} \mathrm{O}_{2}$ reaction. After nuclear staining with methyl green or hematoxylin, sections were embedded in plastic medium.

In order to estimate the extent of masking of endogenous biotin, negative control staining without primary antibody was performed in each case.

Evaluation of the staining results was performed, taking into account the extent of staining of endogenous biotin in the negative control, in terms of number of positive cells $(\mathrm{N})$, density of immunoreaction (D) and background staining. Expression was evaluated as a score that was the product $(\mathrm{N} \times \mathrm{D})$ of graded number of positive cells $(\mathrm{N})$ and graded density of immunoreaction (D), and is shown in Table 4.

\section{Results}

\section{Morphological changes of leukemic cells in PBTS}

Shrinkage of leukemic cells was noted in H.E.-stained sections of PBTS in comparison with leukemic cells in Giemsa-stained smear specimens. Under high power view (objective $\times 100$, oil) it was easier to observe nuclear figures of leukemic cells in PBTS than in the smear specimens (Fig. 2). In cases of B-CLL, leukemic cells were aggregated.

\section{Phenotype of leukemic cells in PBTS}

As shown in Fig. 3, the CD3-positive, CD5-positive and CD4-positive phenotype of leukemic ATLL cells was 
Table 3. Ki67 labeling index in PBTS by three hrs and more than six hrs of sedimentation and coagulation of leukemic cells

\begin{tabular}{|c|c|c|c|c|c|c|c|c|c|}
\hline \multirow{2}{*}{ Duration of sedimentation } & \multicolumn{9}{|c|}{ Ki67 labeling index (\%) in 3 cases of chronic type ATLL } \\
\hline & \multicolumn{3}{|c|}{ Case 1} & \multicolumn{3}{|c|}{ Case 2} & \multicolumn{3}{|c|}{ Case 3} \\
\hline $3 \mathrm{hr}^{\# 1}$ & 29 & 34 & 41 & 35 & 35 & 32 & 52 & 64 & 54 \\
\hline more than $6 \mathrm{hr}^{\# 2}$ & 26 & 24 & 25 & 23 & 18 & 26 & 42 & 36 & 41 \\
\hline
\end{tabular}

Wilcoxon matched-pairs signed-ranks test, $\mathrm{p}<0.001$

\#1: Three hours sedimentation before fixation was performed in preparing PBTS.

\#2: More than six hours sedimentation before fixation was performed in preparing PBTS.
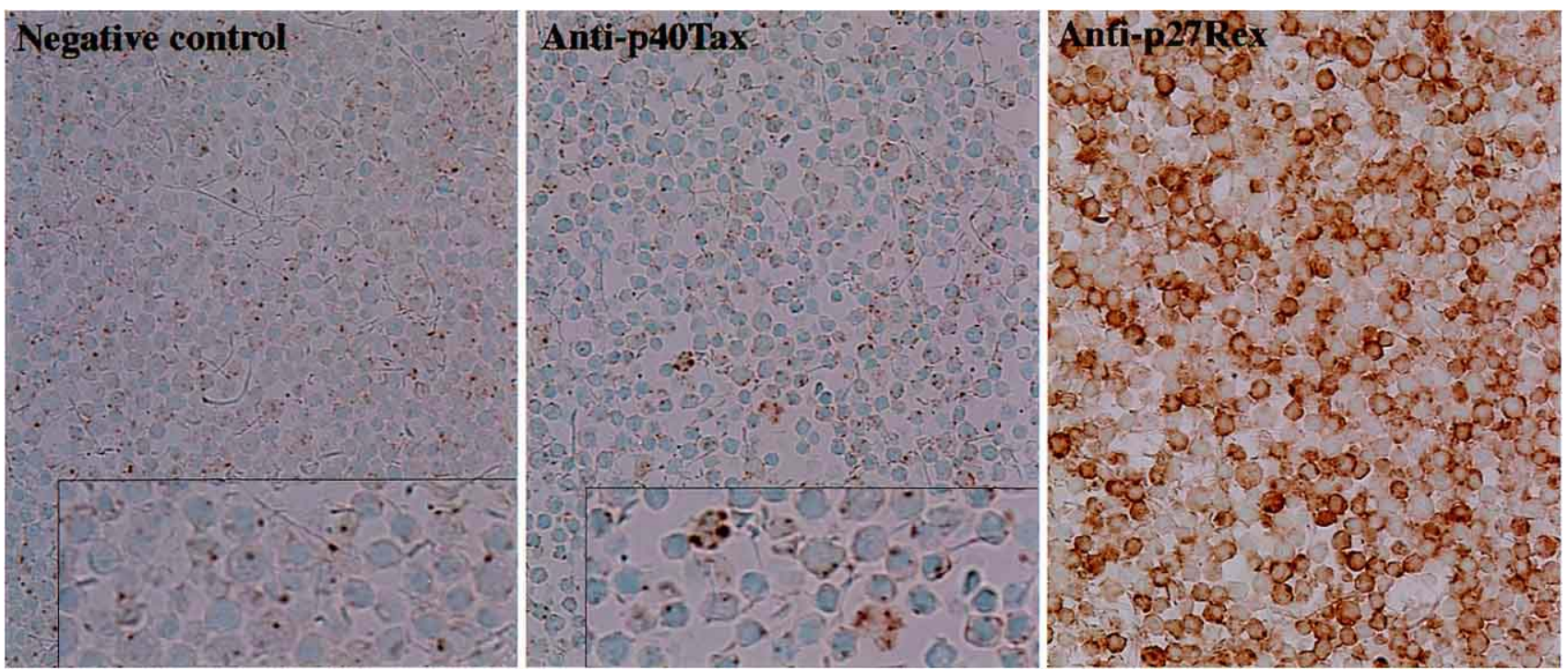

Fig. 4. Modified ImmunoMax of Tax and Rex with negative control stain in a case (Case J) of acute type ATLL (Original objective $\times 40$, inserted high power view: $\times 4$ original figure). In the negative control, immunoreactivity of endogenous biotin was noted. Immunostaining with anti-p40Tax antibody (WATM-1) was weak, but obviously stronger than that of endogenous biotin. In high power view, large granular and weak diffuse stain in scant cytoplasm was noted in comparison with the negative control. Immunostaining with anti-p27Rex (Rec-6) was strong.

detected by the AR pIHC. However, in a case of acute type ATLL after chemotherapy (Case A) the phenotype of leukemic cells could not be identified, because the mononuclear cells comprised CD3-positive, CD5-positive, CD79a-positive, CD8-positive and CD68-positive cells. In cases of B-CLL, the CD5-positive and CD79a-positive phenotype of B-CLL leukemic cells was detected.

\section{Proliferating cells in PBTS}

For the three cases of chronic type ATLL (Cases 1 to 3), Ki67 labeling indexes of leukemic cells are presented in Table 3 for PBTS prepared either with $3 \mathrm{hr}$ or with longer than $6 \mathrm{hr}$ of sedimentation and coagulation time in injectors maintained vertically. The Ki67 labeling index was significantly higher in PBTS prepared with $3 \mathrm{hr}$ of sedimentation and coagulation before fixation than in PBTS prepared with longer than $6 \mathrm{hr}$ of sedimentation and coagulation (Wilcoxon matched-pairs signed-ranks test, $\mathrm{p}<0.001$ ), indicating proliferation of leukemic cells during the sedimentation and coagulation process.

The Ki67 labeling index in the ATLL cases varied from case to case (Table 4). No Ki67-positive nuclei were seen in a case of ATLL after chemotherapy (Case A). There were 3 cases of ATLL with a quite low Ki67 labeling index.

\section{Modified ImmunoMax of Tax and Rex in PBTS}

Immunoreactivity for anti-Tax and anti-Rex antibodies was evaluated for each case, taking into account the extent of masking of endogenous biotin in the negative control samples (Fig. 4a) (Table 4).

After staining with anti-Tax antibody (WATM-1), leukemic cells in Cases C and F of ATLL did not reveal immunoreactivity. In the other six cases of ATLL, weak staining for Tax was observed in leukemic cells (Table 4, Fig. 4b). The score of anti-Tax immunostaining increased in the acute and chronic cases of ATLL in parallel with the Ki67 labeling index (Table 4). No immunostaining with anti-Tax antibody was noted in the three cases of B-CLL.

As shown in Fig. 4c and in Table 4, leukemic cells in all cases, including ATLL and B-CLL, showed markedly stronger immunoreactivity with anti-Rex antibody (Rec-6) than with anti-Tax antibody.

\section{Discussion}

We have developed a modified ImmunoMax method to 
Table 4. Proliferating cells rate and evaluation of modified ImmunoMax of Tax and Rex

\begin{tabular}{|c|c|c|c|c|c|c|c|c|c|}
\hline \multirow{2}{*}{ No. } & \multirow{2}{*}{ Diagnosis. } & \multirow{2}{*}{$\begin{array}{c}\text { Ki67 LI } \\
\text { Index (\%) }\end{array}$} & \multicolumn{3}{|c|}{ Anti-p40Tax } & \multicolumn{4}{|c|}{ Anti-p27Rex } \\
\hline & & & $\mathrm{N}^{\# 1}$ & $\mathrm{D}^{\# 2}$ & Score $^{\# 3}$ & $\mathrm{~N}^{\# 1}$ & $\mathrm{D}^{\# 2}$ & Score $^{\# 3}$ & $\mathrm{Back}^{\# 4}$ \\
\hline A & Acute type & 0 & 2 & 1 & 2 & 2 & 3 & 6 & +++ \\
\hline $\mathrm{C}$ & Acute type & 0.8 & 0 & 0 & 0 & 4 & 1 & 4 & +++ \\
\hline $\mathrm{E}$ & Acute type & 8.3 & 3 & 1 & 3 & 4 & 1 & 4 & - \\
\hline $\mathrm{J}$ & Acute type & 16 & 4 & 1 & 4 & 4 & 2 & 8 & - \\
\hline B & Chronic type & 0.2 & 1 & 1 & 1 & 2 & 3 & 6 & + \\
\hline $\mathrm{D}$ & Chronic type & 8.6 & 2 & 1 & 2 & 4 & 2 & 8 & + \\
\hline $\mathrm{G}$ & Chronic type & 17 & 4 & 1 & 4 & 4 & 2 & 8 & - \\
\hline $\mathrm{F}$ & Chronic type & 30 & 0 & 0 & 0 & 4 & 1 & 4 & - \\
\hline $\mathrm{H}$ & B-CLL & 7 & 0 & 0 & 0 & 3 & 2 & 6 & - \\
\hline I & B-CLL & 26 & 0 & 0 & 0 & 4 & 1 & 4 & - \\
\hline $\mathrm{K}$ & B-CLL & 7.1 & 0 & 0 & 0 & 4 & 1 & 4 & - \\
\hline
\end{tabular}

Ki67 labeling index: Rate of Ki67 antigen-positive proliferating cells.

\#1: Number of positive cells. 0, No positive cells; 1 , Rare positive cells; 2, A few psoitive cells; 3, Some positive cells; 4 , Many posiitve cells. \#2: Density of immunostain. 0, No stain; 1, Weak stain; 2, Moderate stain; 3, Strong stain.

\#3: Score of immunostain $=($ Number of positive cells $) \times($ Density of immunostain $)$

\#4: Background staining. -, No stain; +, Weak stain; ++, Moderate stain; +++, Strong stain.

Correlation of Ki67 labeling index and score of anti-p40Tax antibody was significant in the ATLL cases except cases A and F (Fisher's Z-transformation, $\mathrm{r}=0.949, \mathrm{n}=6, \mathrm{z}=3.158, \mathrm{p}=0.0016$ ).

detect an extremely small amount of HTLV-1 Tax protein in paraffin sections of biopsy or surgical materials $[3,4,9]$. We have also established a simplified catalyzed signal amplification (CSA) system that avoids non-specific reaction with endogenous biotin by using an autoimmunostainer [4], although the previous method was applied in this study. In order to study HTLV-1 Tax protein in leukemic cells in peripheral blood, it was necessary to prepare tissue sections of these cells. For this purpose, we used PBTS.

It was shown in this study that PBTS method is a valid one to sample leukemic cells in peripheral blood. Morphological features of leukemic cells have been examined on air-dried peripheral blood smear specimens, which are usually stained by Giemsa solution. However, unstained peripheral blood smear specimens cannot be preserved well for long periods. Currently, the immunological phenotype of leukemic cells may be examined by means of flow cytometry. Stepwise freezing of leukemic cells can also supply viable leukemic cells after long preservation times. However, these methods need handling of peripheral blood to extract leukemic cells, so that such studies cannot often be performed to monitor the clinical course of patients. On the other hand, PBTS can be routinely prepared in the clinic with the cooperation of a surgical pathology laboratory. As shown in Fig. 3, the immunological phenotype of leukemic cells can be evaluated by means of a recently developed AR pIHC that should be available in a small surgical pathology laboratory in a hospital. PBTS can be treated as a biopsy or surgical sample of peripheral blood.

Shrinkage of leukemic cells was observed in PBTS (Fig. 2), although their size was similar to that of leukemia/ lymphoma cells in biopsy or surgical material specimens for microscopy. For all three cases studied, higher Ki67 labeling indexes were shown in leukemic cells in PBTS prepared after $3 \mathrm{hr}$ of sedimentation and coagulation compared with after longer than $6 \mathrm{hr}$ of sedimentation and coagulation (Table 3), suggesting that Ki67 antigen-positive proliferating cells were induced during sedimentation and coagulation of leukemic cells. Low and high Ki67 labeling indexes were found in both acute type and chronic type cases of ATLL. The reproliferation of leukemic cells in PBTS may reflect the capacity of leukemic cells undergoing mitosis in vivo, although further studies on the proliferation of leukemic cells will be necessary to confirm this.

It was found in this study that scores of anti-Tax staining obtained by using a modified ImmunoMax method paralleled the Ki67 labeling index in ATLL leukemic cells in cases except cases A and F (Table 4, Fisher's Z-transformation: $\mathrm{r}=0.949, \mathrm{p}=0.016$ ). Although it is unknown whether ATLL leukemic cells proliferate in the peripheral blood of patients, these ATLL leukemic cells had a capacity for reproliferation and expressed a small amount of Tax. The relationship between expression of Tax and Ki67 labeling index in these ATLL leukemic cells in PBTS suggests that Tax induces reproliferation of ATLL leukemic cells, as suggested previously by Yoshida et al. [24]. However, ATLL leukemic cells in a case of chronic type with $30 \%$ Ki67 labeling index (Case F in Table 4) and in a case of acute type with $0.8 \%$ Ki67 labeling index (Case C in Table 4) did not express Tax. In these cases of ATLL, the HTLV-1 provirus might be defective $[10,11,21]$. Secondary genetic changes induced by Tax $[2,12]$ may play a major role in proliferation of leukemic cells. On the other hand, in a case after chemotherapy (Case A), some cells displayed weak expression of Tax in spite of the absence of Ki67 antigen-positive cells. Under the stress of chemo- 
therapy, the HTLV-1 provirus might initiate reproduction of HTLV-1 or production of related protein [1, 6, 24].

Although ATLL leukemic cells have been reported not to express HTLV-1 Tax $[11,16]$, we found that these cells express an extremely small amount of Tax, which could be visualized by a supersensitive immunohistochemical method by means of modified ImmunoMax, during reproliferation. This extremely small amount of Tax may be enough to induce leukemic cell proliferation.

Finally, immunoreactivity to anti-p27Rex antibody (Rec-6) was also found in leukemic cells from the three cases of B-CLL. Because the immunostaining might reflect hyperexpression of molecules with the same epitope as labeled by Rec- 6 , this shows that the modified ImmunoMax using Rec-6 is not specific for HTLV-1 Rex $[3,4]$ and cannot be applied for differential diagnosis of ATLL, although p27Rex has various functions [18].

\section{Acknowledgments}

This study was supported in part by a Grant-in-Aid from the Ministry of Education, Culture, Sports, Science and Technology, Japan, \#13557017(B) to KH. We also with to thank Rie Murayama, Shouko Yamauchi, Yukari Nishimura and Yoshiko Arimura (Second Department of Pathology, Kagoshima University Faculty of Medicine; Prof. Suguru Yonezawa) for their expert processing of PBTS materials and for their skillful help in immunohistochemistry.

\section{References}

1. Chosa, T., Yamamoto, N., Tanaka, Y., Koyanagi, Y. and Hinuma, Y. (1982) Infectivity dissociated from transforming activity in a human retrovirus, adult T-cell leukemia virus. Gann $73 ; 844-847$

2. Haller, K. and Jeang, K. T. (2003) Clastogenic and aneugenic DNA damage in HTLV-1 Tax-expressing cells. In "Two Decades of Adult T-cell Leukemia and HTLV-1 Research" Monograph on Cancer research No. 50 ed. by K. Sugamura, T. Uchiyama, M. Matsuoka and M. Kannagi, Japanese Scientific Societies Press Tokyo, S. Karger AG, Basel, pp. 93-102.

3. Hasui, K., Sato, E., Tanaka, Y., Yashiki, S. and Izumo, S. (1997) Quantitative highly-sensitive immunohistochemistry (Modified ImmunoMax) of HTLV-1 p40tax and p27rex proteins in HTLV1 -associated non-neoplastic lymphadenopathy (HANNLA) with estimation of HTLV-1 dose by polymerase chain reaction. Dendritic Cells 7; 19-27.

4. Hasui, K., Sato, E., Tanaka, Y., Yashiki, S. and Izumo, S. (1997) The modified ImmunoMax of HTLV-1 Tax protein can label HTLV-1-related cases of T-cell lymphomas. In "Lymphoreticular Cells and Diseases, Proceedings of the Fifth Korean-Japanese Lymphoreticular Workshop" ed. by J. D. Lee and K. Takahashi, Hematolymphoreticular Study Group, The Korean Society of Pathologists, Seoul, Korea, pp. 326-336.

5. Hasui, K., Takatsuka, T., Sakamoto, R., Matsushita, S., Tsuyama, S., Izumo, S. and Murata, F. (2002) Improvement of supersensitive immunohistochemistry with an autostainer: simplified catalyzed signal amplification (CSA) system. Histochem. J. 34; 215222.

6. Hinuma, Y. (1982) Association of a retrovirus (ATLV) with adult $\mathrm{T}$ cell leukemia: review of serologic studies. In "Adult T Cell
Leukemia and Related Disease" GANN Monograph on Cancer Research No. 28. ed. by M. Hanaoka, K. Takatsuki and M. Shimoyama, Japan Scientific Societies Press Tokyo, Plenum Press, New York and London, pp. 211-218.

7. Inoue, M., Matsuoka, M., Yamaguchi, K., Takatsuki, K. and Yoshida, M. (1998) Characterization of mRNA expression of I Kappa B alpha and NF Kappa B subfamilies in primary adult Tcell leukemia cells. Jpn. J. Cancer Res. 89; 53-59.

8. Jin, D. Y. and Jeang, K. T. (1997) Transcriptional activation and self-association in yeast: protein-protein dimerization as a pleiotropic mechanism of HTLV-I Tax function. Leukemia (Suppl 3); 3-6.

9. Marin, O., Hasui, K., Remondegui, C., Sato, E., Aye, M. M., Takenouchi, N., Izumo, S. and Tajima, K. (2002) Adult T-cell leukemia/lymphoma in Jujuy, north-west Argentina. Pathol. Int. 52; 348-357.

10. Matsuoka, M., Tamiya, S., Takemoto, S., Yamaguchi, K. and Takatsuki, K. (1997) HTLV-I provirus in the clinical subtypes of ATL. Leukemia (Suppl. 3); 67-69.

11. Matsuoka, M. (2003) Somatic alterations in adult T-cell leukemia cells. In "Two Decades of Adult T-cell Leukemia and HTLV-1 Research" Monograph on Cancer research No. 50 ed. by K. Sugamura, T. Uchiyama, M. Matsuoka and M. Kannagi, Japanese Scientific Societies Press Tokyo, S. Karger AG, Basel, pp. 115125.

12. Miyake, H., Suzuki, T., Kirai, H. and Yoshida, M. (1999) Transactivator Tax of human T-cell leukemia virus type 1 enhances mutation frequency of the cellular genome. Virology 253; 155161.

13. Miyoshi, I., Taguchi, H., Kuronishi, I., Yoshimoto, S., Ohtsuki, Y., Shiraishi, Y. and Akagi, T. (1982) Type C virus-producing cell lines derived from adult $\mathrm{T}$ cell leukemia. In "Adult $\mathrm{T}$ Cell Leukemia and Related Disease" GANN Monograph on Cancer Research No. 28. ed. by M. Hanaoka, K. Takatsuki and M. Shimoyama, Japan Scientitic Societies Press Tokyo, Plenum Press, New York and London, pp. 219-228.

14. Mulloy, J. C., Kislyakova, T., Cereseto, A., Casareto, L., LoMonico, A., Fullen, J., Lorenzi, M. V., Cara, A., Nicot, C., Giam, C. and Franchini, G. (1998) Human T-cell lymphotrophic/ leukemia virus type 1 Tax abrogates p53-induced cell cycle arrest and apoptosis through its CREB/ATF functional domain. J. Virol. $72 ; 8852-8860$.

15. Ohtani, K. and Nakamura, M. (2003) Molecular mechanisms of Tax-mediated cell growth of human T lymphocytes. In "Two Decades of Adult T-cell Leukemia and HTLV-1 Research" Monograph on Cancer research No. 50. ed. by K. Sugamura, T. Uchiyama, M. Matsuoka and M. Kannagi, Japanese Scientific Societies Press, Tokyo, S. Karger AG, Basel, pp. 43-60.

16. Okayama, A. and Stuver, S. O. (2003) Long-term follow-up of HTLV-1 carrier. In "Two Decades of Adult T-cell Leukemia and HTLV-1 Research" Monograph on Cancer research No. 50. ed. by K. Sugamura, T. Uchiyama, M. Matsuoka and M. Kannagi, Japanese Scientific Societies Press, Tokyo, S. Karger AG, Basel, pp. $127-139$.

17. Pise-Masison, C. A., Radonovich, M., Sakaguchi, K., Appella, E. and Brady, J. N. (1998) Phosphorylation of p53: a novel pathway for $\mathrm{p} 53$ inactivation in human T-cell lymphotrophic virus type 1transformed cells. J. Virol. 72; 6348-6355.

18. Shida, H. and Hakata, Y. (2003) Multiple roles of cellular export machinery in HTLV-1 Rex functioning. In "Two Decades of Adult T-cell Leukemia and HTLV-1 Research" Monograph on Cancer research No. 50. ed. by K. Sugamura, T. Uchiyama, M. Matsuoka and M. Kannagi, Japanese Scientific Societies Press, Tokyo, S. Karger AG, Basel, pp. 61-72.

19. Suzuki, T., Kitano, S., Matsushime, H. and Yoshida, M. (1996) HTLV-1 Tax protein interact with cycline dependent kinase inhibitor p15INK4A and counteracts its inhibitory activity towards 
CDK4. EMBO J. 15; 1607-1614.

20. Takatsuki, K., Yaguchi, K., Watanabe, T., Mochizuki, M., Kiyokawa, T., Mori, S. and Miyata, N. (1992) Adult T-cell leukemia and HTLV-1 related diseases. In "Advances in Adult T-cell Leukemia and HTLV-1 Research" Gann Monograph on Cancer Research No. 39. ed. by K. Takatsuki, Y. Hinuma and M. Yoshida, Japan Scientific Societies Press, Tokyo, pp. 1-15.

21. Tamiya, S., Matsuoka, M., Etoh, K., Watanabe, T., Kamihira, S., Yamaguchi, K. and Takatsuki, K. (1996) Two types of defective human T-lymphotropic virus type I provirus in adult T-cell leukemia. Blood 88; 3065-3073.

22. Tanaka, Y., Masuda, M., Yoshida, A., Shida, H., Nyunoya, H., Shimotohno, K. and Tozawa, H. (1992) An antigenic structure of the trans-activator protein encoded by human T-cell leukemia virus type-I (HTLV-I), as defined by a panel of monoclonal antibodies. AIDS Res Hum Retroviruses 8; 227-235.

23. Tanimura, A., Dan, S. and Yoshida, M. (1998) Cloning of novel ispforms of human Gli2 oncogene and their activities to enhance tax-dependent transcription of human T-cell leukemia virus type1 genome. J. Virol. 72; 3958-3964.

24. Yoshida, M., Miyoshi, I. and Hinuma, Y. (1985) Isolation and characterization of retrovirus (ATLV) and its association with adult $\mathrm{T}$ cell leukemia. In "Adult $\mathrm{T}$ Cell Leukemia and Related Disease" GANN Monograph on Cancer Research No. 28. ed by M. Hanaoka, K. Takatsuki and M. Shimoyama, Japan Scientitic Societies Press Tokyo, Plenum Press, New York and London, pp. 229-237.

25. Yoshida, M. and Fujisawa, J. (1992) Positive and negative regulation of HTLV-1 gene expression and their roles in leukemogenesis in ATLL. In "Advances in Adult T-Cell Leukemia and HTLV-1 Research" Gann Monograph on Cancer Research No. 39. ed. by K. Takatsuki, Y. Hinuma and M. Yoshida, Japan Scientific Societies Press, Tokyo, pp. 217-236. 